\title{
La vocación intelectual en la obra de Luis Fabio Xammar
}

La desaparición inesperada y sentida de Luis Fabio Xammar, cuyas altas virtudes y talentos serán siempre recordados, con la memoria que se reserva para los espíritus privilegiados como el suyo, hace meditar en el destino adverso que parece presidir la vocación crítica en el Perú del siglo XX.

\section{La vocación crítica en el Perú.-}

La muerte o la actividad extrañala menester de la crítica o la investigación literaria, «segó e desvío precoz y prematuramento la tarea de los críticos de las últimas generaciones. Basta la referencia a Enrique A. Carrillo, autor de originales atisbos críticos, entre los que destacan su "descubrimiento" de José María Eguren y la ubicación de su poesía desde Colónida o en el prólogo de "La canción de las figuras" (1916) y quien, captado por el periodismo y la burocracia dejó de insistir en esa su auténtica vocación. Es inevitable recordar la figura señera de Alfredo González Prada, que tal vez fué la más grande vocación crítica de nuestra época, volćada y absorbida unilateralmente en la exégesis y la revisión de la obra paterna, disposición literaria que la muerte truncó en forma trágica e incomprensible en el preciso momento en que -en plena madurez- tomaba su tarea el surco y la senda propia. Hace 20 años, Adalberto Varallanos llegó, con una clarividencia precoz, a delinear verbalmente los problemas de la nueva literatura pero la muerte temprana no permitió siquiera que llegara a perfilar por escrito la obra perdu- 
rable que pudo haber forjado. No hace mucho, Carlos Pareja Paz Soldán, extraordinario talento discriminador de valores culturales, desapārecía antes de los 30 años en pleno fervor de valoraciones críticas, de las que ha dejado fragmentos inapreciables.

A otros la muerte respetó o ha respetado; mas por una razón u otra, dejaron el campo de la crítica, se alejaron de la problemática literaria, después de escribir libros o ensayos fundamentales y de abrir huellas profundas, y dedicaron sus capacidades a los problemas de la historia, del derecho, de la sociología, del periodismo o de la política.

El culto de la crítica literaria tampoco fué aforiunado en el siglo XIX 0 en las generaciones del comienzo del presente. No puede pedirse a Ricardo Palma, que fué el creador por excelencia, que se erigiera en el crítico de su generación, ni así lo pretendió nunca en "La bohemia de mi tiempo"; aquí se define solamente como el memorialista insigne. Manuel González Prada esporádicamente define y comenta alguna gran figura nacional como Chocano y muchas extranjeras, pero insistiendo en la admonición moral o política. Si bien es cierto que alentó con éxito favorable un grupo juvenil en la actividad literaria, también es verdad que como Chocano, tenía más vocación de caudillo que de crítico. Javier Prado y Francisco García Calderón volcaron sus inquietudes en el comentario crítico de obras y de autores; pero luego, al entrar en la madurez, acudieron al llamado de otras inquietudes culturales.

Sólo en nuestros días es persistente en muchos autores una dedicación señera al estudio de los problemas literarios, en publicaciones y en la cátedra, en el libro y en la monografía o el ensayo. No necesito mencionar los nombres deglos queiestán en läfarea"a veces dura e incomprendida. Ha bastado la referencia a los que la muerte sorprendió sin alerta.

Ahora Luis Fabio Xammar confirma ese adverso destino, que interrumpe una trayectoria brillante en la investigación literaria. Aparte de su obra poética, quedan libros fundamentales de investigación como los dedicados a Yerovi, a Valdelomar y a Manuel Atanasio Fuentes, éste último inédito; quedan también multitud de ensayos publicados o en vías de serlo y una obra parcialmente trabajada sobre los románticos peruanos del 48.- Caviedes, Concolorcorvo, Segura, Corpancho, Palma, Juan de Arona y otros románticos; Chocano, Bustamante y Ballivián, además de Valdelomar, Yerovi y Fuentes, merecieron principalmente su enfocamiento crítico y su análisis certero de peculiaridades y ubicación huma. na, en el espacio y en el tiempo. 


\section{Peruanismo.-}

Lo que más caracteriza a Xammar es su afán peruanista y hay que insistir en señalar esta condición por que en ella Luis Fabio es ejemplar. En un pais en que todo o la mayor parte de las cosas está por hacer, debe orientarse la investigación hacia los problemas nacionales. No hay excusa para el que, bien dotado de aptitudes y nacido en este sue. lo, aparta la vista de nuestras realidades, por desdén, por comodidad o por desidia. Así lo sentía Xammar escribiendo a propósito de Palma: "Hoy que las crisis sociales nos obligan a un emocionado e íntimo balance de nuestras realidades, sentimos la enorme intensidad dramática de lo peruano que significó Palma". El Perú y su destino literario era en Xammar una verdadera obsesión; su vigilia se volcaba en el estudio y examen de nuestro pasado y nuestro presente literario; sus sueños le permitían vislumbrar una gran obra futura de síntesis de nuestro proceso cultural. "En la literatura como en todos los campos del arte, decía en el mismo estudio sobre Palma, no existen milagros. Se realiza en ella con más crueldad, quién sabe, que en otros aspectos de la vida, la lucha biológica en la que perecen los débiles o bastardos, y perseveran y triunfan aquellos que llevan en su sangre un mensaje fundamental... La tradición de Palma triunfó por que cumplía su papel social e histórico, y porque Palma - profeta de la peruanidad - como el cholo Garcilaso de la Vega - trazaba el dibujo perdurable de nuestra aventura nacional".

\section{Antidogmatismo.-Biblioteca de Letras}

Tiene otra virtud insigne la obra crítica de Xammar. Forzado a ser erudito en algunos estudios, volcaba su talento en disimular el acopio de fría documentación con aleteo de donaire y de humor. Eludía siempre el helado academismo y el dogmatismo pretensioso. Aunque de una formación profunda y severamente universitaria, apartaba siempre todo lo que fuera doctoral. El libro que pudo titularse "Vida y obra de Abraham Valdelomar" lo llamó ágilmente "Valdelomar-signo". El que pudo llamarse "Exégesis de Yerovi" se tituló llanamente "Valores humanos en la obra de L. Y.". Lo que pudo denominarse "Ensayo crítico sobre Concolorcorvo", fué rotulado simplemente "Perspectiva de Concolorcorvo, pícaro". A un completísimo y precioso estudio sobre Manuel Atanasio Fuentes, aparecido por fragmentos en una revista de derecho internacional, quería nombrarlo discreta y modestamente "Apuntes para una biografía del Murciélago". 
Nada estaba más lejos de su espíritu que los engolamientos y las forzadas y vacías pompas a que son afectos los espíritus mediocres o los falsos valores. Actuaba y hablaba colocando su yo en un lugar digno pero recatado. Nunca alardeaba de triunfos, de sapiencia ni de exitosas empresas personales. Su orgullo bien sentado lo hacía remiso tanto a la sumisión como al auto-elogio. Lo afectaba profundamente la incomprensión o la injusticia, pero nunca salió de sus labios una queja amarga o un reproche vengativo. Frente a la inconsecuencia o a la maldad de los demás, callaba serenamente. Usaba una pronta y amable ironía para recibir ese elogio encendido y brusco que desconcierta al más avezado. Con humorística destreza, neutralizaba momentos álgidos y desagradables que surgen en reuniones o cenáculos. Era pleno su afán de dar de sí, de agradar, de ayudar, de invitar a la tarea espiritual, sin reservas ni medidas. Entendía la vocación intelectual no como un privilegio de elegido sino como un deber de servicio.

\section{Método crítico.-}

La muerte ha sorprendido a Xammar en la plena madurez de su ta. lento, cuando se preparaba, con la fruición que sabía poner en sus planes y en sus trabajos, a despojarse de las trabas administrativas y menudas que lo habían estorbado $y$ desviado de sus intenciones intelectuales. Ya no era el crítico de ocasión que comenta el libro que cae en sus manos y que hace consideraciones actuales o inactuales, con un criterio extraño a la apreciación de la obra de arte en el tiempo o en el espacio o a la vinculación con los contamporáneos o con los precedentes. Era ya el crítico que Javanzabal concientementelpor "entre la fronda de autores y de libros en una determinada época, armado de un método diestramente aplicado y con una estimativa segura abtenida a través de sus lecturas y de pacientes estudios de literatura, de historia y de filosofía. Su cultura integral y especial se había afirmado en la preparación del dictado de las cátedras y en las pacientes investigaciones que había practicado, en los últimos tiempos, en la Biblioteca Nacional de Lima, principalmente, antes y después del siniestro que la redujo casi to. talmente a cenizas. Comprendía muy hondamente, con Bernard Fay, que "es preciso mantener vivas las grandes obras a medida que el tiempo trabaja en destruírlas". Por eso, iniciando Xammar un estudio cabal que preparaba y que ha quedado parcialmente inconcluso, sobre los románticos peruanos de 1848, decía: "Recordándolos ahora, pensamos en lo conveniente que sería abrir en el Perú el, debate en torno a su mensaje, para que cuando venga el año 1948 con sus posibilidades centenarias, 
estemos de acuerdo sobre todas las cosas con las que ellos estaban en desacuerdo, y podamos preparar sus fojas de servicios para la indudable eternidad a que tienen derecho".

Xammar había superado ya la crítica que sólo se detiene en la biografía del personaje o del autor, que merodea simplemente en torno de la obra o del hombre. Ya se puede advertir esta superación en sus tomos sobre Yerovi y Valdelomar, en que anima a sus criticados dentro de su ambiente, dentro de los ideales de su época, de sus tendencias y de las de sus contemporáneos. Manejaba tan diestramente los libros como los periódicos y las revistas. Sopesaba en todo lo que significan para la crítica moderna, y sobre todo en un medio de escasa producción de libros, el valor vital de estudios dispersos, de apuntes aparentemente insignificantes, de datos perdidos, de informaciones olvidadas, de aprontes valiosos, de incipientes esfuerzos, de trabajos inconclusos, que se encuentran desperdigados en las páginas del periodismo que pasa. Muy poco de todo eso encuentra el investigador en los libros, casi nada. El libro traduce algo concluído, y con frecuencia la cima lograda - malograda. En cambio, el periódico o la revista significan para el investigador la fuente de una vida que palpita en medio de imperfecciones, esfuerzos, proyectos, divergencias, convergencias de humanos intereses, lo que nace y lo que muere, el ondulante acontecer. Así lo entendió Xammar con su sentido moderno de la investigación literaria y así habría de descubrir el paso de la vida al pensamiento y la reconstrucción de la vida a través del pensamiento. etras

\section{Vivencia y creación.-}

\section{"Jorge Puccinelli Converso"}

Era extraordinaria la efusión que Xammar sabía poner en sus estudios. Contagiaba la simpatía con que miraba a los autores elegidos y aquí radica precisamente el secreto de su buen éxito en la apreciación de nuestar historia literaria y del acierto en el enjuiciamiento de sus personajes. Supo realizar y llevar a la práctica el consejo de que "el crítico debe comprender la vida de la obra por la vida propia de él como crítico; su estudio tiene como base la simpatía; desprende un juicio moral de la intensidad de la lucha entre el instinto vital y el sentido moral", según ha establecido Van Thieghem. De aquí la extraña movilidad y el atractivo que desprenden un Leonidas Yerovi, casi olvidado antes del estudio de Xammar, y un Abraham Valdelomar, sin exégeta integral hasta el ensayo de Xammar. Podría reunirse esos trabajos bajo un título común que sería el mismo que luce el libro famoso de Guillermo Dilthey en que agrupa sus ensayos críticos sobre Novalis, Goethe y Lessing, 
"Das Erlebnis und die Dichtung", el sentido vital y la poesía, la vivencia y la creación poética.

\section{Poesía y enseñanza.-}

Pero al tratar de Xammar, no sólo debemos detenernos en el crítico. Ha dejado igualmente una apreciable e intensa obra poética. Dos ediciones de su libro "Wayno" - y antes "Las voces armoniosas" - han recogido un conjunto logrado de poemas de un fino lirismo que busca Y encuentra asidero en las realidades peruanas. Quiso Xammar integrar un delicado sentido de la tierra con una romántica y moderna nota de amor o de angustia. No estuvo exenta su musa de influencias notables - desde Juan Ramón Jiménez hasta García Lorca - , pero como dice Malraux, "para encontrar su forma, un artista tiene que partir no de la vida, sino de la forma de otro artista, y sólo después llega a expresar su propia vida... "Su libro inédito "Alta Niebla" afirma ya, finalmente, una aptitud poética libre de extraños influjos, rica en experiencias y, a juzgar por los breves fragmentos publicados, constituye su definitiva consagración como poeta. Una desazón interior, una angustia que no halla sosiego, tal vez el presentimiento de un final prematuro, la inconformidad frente al designio del destino, presiden y caracterizan - dentro de una forma lograda y pulcra - la originalidad poética de Xammar y lo destacan como un valor sobresaliente en las antologías del porvenir.

$\mathrm{Si}$ un destino adverso ha conspirado contra el desarrollo de la crítica y la investigación literaria en el Perú contemporáneo, si esa misma e insuperable fuerza has sustraído de là vida cultural, peruana a uno de sus más calificados representantes cuando nuestras esperanzas eran más fundadas, hay que hacer votos por que el examen de las capacidades notabilísimas, de las nobles intenciones, de las altas virtudes y de las maduras realizaciones de Luis Fabio Xammar, sirva para iluminarnos en el estado de crisis de los altos estudios y de la investigación literaria por la que atravesamos. Su espíritu ha de velar, latente en las páginas fecundas que deja escritas y desde la otro banda de la; alta e insondable niebla que lo separa de nosotros, por que sea realidad alcanzable y próxima la valoración sistemática y definitiva de las grandes figuras y de las obras perdurables de la literatura peruana.

Esto es lo que importa: que su espíritu se haga carne y realidad en las nuevas generaciones, que su actitud arraigue como un modelo fecundo de ser y de estar. No importa ya que la obra haya quedado inconclusa. Con la propia ayuda de estas frases suyas que siguen llegamos casi a reconciliarnos con la dura realidad de la pérdida de este hombre 
de letras en plena producción, de este dilecto espíritu, de este ejemplar forjador de cultura. Así dicen estas palabras de Xammar: "Lo que más avalora la obra que intenta ser humana es su propio inacabamiento; su condición transitoria perfectible con el tiempo y con las nuevas nociones que de la vida, sólo este tiempo pondrá en evidencia. La "obra acabada" no es sino un bello espejismo, a veces el orgullo coronando un esfuerzo intenso".

\section{Estuardo Núñez.}

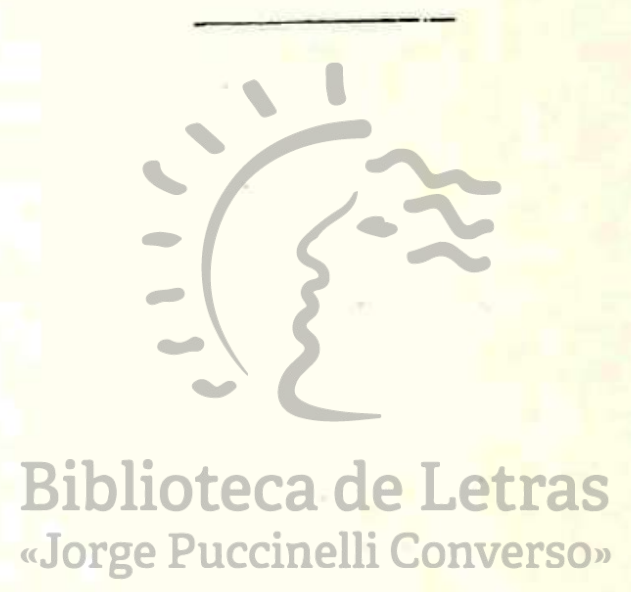

